\title{
Electrodeposition conditions-dependent crystal structure, morphology and electronic properties of Bi films
}

\author{
Alexander Fedotov ${ }^{a, b}$, Vladislav Shendyukov ${ }^{c}$, Ludmila Tsybulskayac ${ }^{c}$, Sergey Perevoznikov , \\ Mengge Dong ${ }^{\mathrm{d}}$, Xiangxin Xue ${ }^{\mathrm{d}}$, Xiating Feng ${ }^{\mathrm{e}}$, M.I. Sayyed ${ }^{\mathrm{f}, \mathrm{g}}$, Tatiana Zubar ${ }^{\mathrm{h}, \mathrm{i}}$, \\ Alex Trukhanov ${ }^{h, i, j}$, Daria Tishkevich ${ }^{h, i, k, *}$ \\ ${ }^{a}$ Computer Modelling Department of Physics Faculty, Belarusian State University, Minsk 220030, Belarus \\ ${ }^{\mathrm{b}}$ Laboratory of Biocompatible Nanoelectronics, University of Tyumen, Tyumen 625003, Russia \\ ${ }^{\mathrm{c}}$ Laboratory of Thin Films Chemistry, Research Institute for Physical Chemical Problems of the Belarusian State University, Minsk 220006, Belarus \\ ${ }^{\mathrm{d}}$ Department of Resource and Environment, Northeastern University, Shenyang 110819, China \\ e Key Laboratory of Ministry of Education on Safe Mining of Deep Metal Mines, Northeastern University, Shenyang 110819, China \\ ${ }^{\mathrm{f}}$ Department of Physics, Faculty of Science, Isra University, Amman, Jordan \\ ${ }^{\mathrm{g}}$ Department of Nuclear Medicine Research, Institute for Research and Medical Consultations (IRMC), Imam Abdulrahman bin Faisal University (IAU), 31441 \\ Dammam, Saudi Arabia \\ h Laboratory of Magnetic Films Physics, SSPA “Scientific and Practical Materials Research Centre of National Academy of Sciences of Belarus”, Minsk 220072, \\ Belarus \\ ${ }^{i}$ Laboratory of Single Crystal Growth, South Ural State University, Chelyabinsk 454080, Russia \\ ${ }^{\mathrm{j}}$ L.N. Gumilyov Eurasian National University, Nur-Sultan 010000, Kazakhstan \\ ${ }^{\mathrm{k}}$ Laboratory of Physics of Low-Dimensional Structures, National University of Science and Technology «MISIS», Moscow 119049, Russia
}

\section{A R T I C L E I N F O}

\section{Article history:}

Received 23 May 2021

Received in revised form 29 July 2021

Accepted 3 August 2021

Available online 5 August 2021

\section{Keywords:}

Bismuth

Electrodeposition

Perchlorate electrolyte

Microstructure

Structure

Electronic properties

\begin{abstract}
A B S T R A C T
The study is devoted to the electronic properties and structure of bismuth films obtained by electrodeposition from high-speed perchlorate electrolyte. Polycrystalline samples were synthesized in acidic perchlorate electrolyte under the $(0.18-70.0) \mathrm{mA} / \mathrm{cm}^{2}$ cathode current density and annealed at $265^{\circ} \mathrm{C}$ in the He gas atmosphere. The structure, microstructure and electron properties of Bi films were characterized using X-Ray diffraction analysis, scanning electron microscopy, and electron backscattered diffraction. Electrical resistance, magnetoresistance, and Hall coefficient were studied at the 5-300 K temperature range under magnetic field up to $8 \mathrm{~T}$. A specific and unexpected behavior has been found concerning the average size and shape of Bi grains with increasing of the current density: the increase in deposition current density up to $70.0 \mathrm{~mA} / \mathrm{cm}^{2}$ contributes to Bi films formation with more isotropic and reduced average grains size. Samples synthesized under $0.18 \mathrm{~mA} / \mathrm{cm}^{2}$ current density after annealing showed electronic properties, including magnetoresistance, similar to those of flawless single-crystals. The differences in the electronic characteristics of Bi films electrodeposited under different currents and electrolyte composition were explained by changes in electronic mobility due to scattering on grain boundaries.
\end{abstract}

(c) 2021 Elsevier B.V. All rights reserved.

\section{Introduction}

Bismuth attracts the researcher's attention due to high mobility of electrons [1,2], numerous applications in sensorics [3-6], and environmental friendliness due to one of the lowest toxicity among heavy elements [7]. Also, Bi could be used as a photo catalyst for

\footnotetext{
* Corresponding author at: Laboratory of Magnetic Films Physics, SSPA “Scientific and Practical Materials Research Centre of National Academy of Sciences of Belarus", Minsk 220072, Belarus.

E-mail address: dashachushkova@gmail.com (D. Tishkevich).
}

environmental pollutants removal, e.g., outstanding visible-light photocatalytic abilities for the reduction of $\mathrm{Cr}(\mathrm{VI})$ to less toxic $\mathrm{Cr}(\mathrm{III})$, high catalytic activity to organic dyes, good photocatalytic degradation of RhB under visible light, admirable and stable photocatalytic activity towards the removal of $\mathrm{NO}$ under $280 \mathrm{~nm}$ light irradiation [8-11]. However, the physical properties of Bi films can vary significantly due to their different microstructure $[12,13]$. Thus, it becomes important to study the effect of synthesis conditions on the electronic properties of polycrystalline Bi films.

Bismuth is a semimetal with a high mobility of charge carriers $\left(10^{2} \mathrm{~m}^{2} /(\mathrm{V} \cdot \mathrm{s})\right.$ or higher at $\left.4 \mathrm{~K}\right)$, which results in high electrical 
conductivity, Seebeck coefficient, and relative magnetoresistance. These properties make Bi-based materials attractive for the development of magnetic field sensors [2,5,6], electrochromic devices [14], thermoelectric coolers $[15,16]$, etc. Numerous researchers report that $\mathrm{Bi}$ electrodes can replace both toxic $\mathrm{Hg}$ electrodes in the potentiometric analysis [10] and $\mathrm{Pb}$ shields for the protection of integrated microcircuits from ionizing radiation [17-19].

Bismuth films can be synthesized by various methods, the most used of which are electrochemical deposition $[2,13,16,20]$, pulsed laser deposition [12,21], vacuum thermal evaporation [22,23], melt spinning [13,24], etc. Pulsed laser deposition allows obtaining highquality thin films due to a high density of grains nucleation. However, due to inhomogeneous energy distribution in the laser beam profile, the inhomogeneity of the film in the center of the beam spot is usually high [25]. Therefore, it may not be useful for the fabrication of large-scale uniform coatings. Samples synthesized by a vacuum thermal evaporation are of very high purity [22] but have a non-uniform thickness on complex surfaces and can be highly expensive. Melt spinning technique allows fast and the cheapest fabrication [24], but the thickness of samples is inhomogeneous by area, and its properties may change with time [26]. Electrochemical deposition combines low costs with the ability to fast cover large complex surfaces $[27,28,62]$.

The efficiency of electrochemical deposition significantly depends on the chemical composition of the electrolyte. A large number of studies have been devoted to the electrodeposition of $\mathrm{Bi}$ films from silicate, pyrophosphate, nitrate, citric, stearic, sulfate, lactate, and other electrolytes [29-33]. Besides, for a specific electrolyte composition, organic additives provide additional control over the film structure [34,35].

There are several options when choosing an electrolyte. The most common bismuth salts are easily hydrolyzed to form insoluble basic salts; therefore, alkaline bismuth electrolytes are not as common as acid electrolytes. Bi electrodeposition from nitric and hydrochloric acids takes place under conditions of much lower irreversibility of the electrode process as compared with perchloric acid electrolytes. The bismuth films obtained in such conditions are large-grained and porous [30,36,37], and prolonged electrodeposition cannot contribute to obtaining smooth and uniform Bi films. It has been shown [38] that perchlorate electrolyte allows receiving of high-quality and dense samples. Perchlorate electrolyte can be easily prepared by bismuth hydroxide or oxide dissolving in perchloric acid. It is important that, unlike other Bi salts, even a strong dilution of bismuth perchlorate solutions does not lead to the precipitation of insoluble deposits of basic salts, which makes perchlorate electrolytes convenient to use and one of the most popular for the study of processes of Bi electrodeposition.

The Bi electrodeposition process depends on the electrolyte composition. A well-known nitrate electrolyte can allow the electrodeposition of uniform coatings in specific conditions, but the deposition is limited in speed down to $12 \mu \mathrm{m} / \mathrm{h}[30,39]$. In this work, we used a recently developed $[36,40]$ perchlorate electrolyte, which is more suitable for practical applications due to a higher growth speed (up to $200 \mu \mathrm{m} / \mathrm{h}$ ) and comparable quality of deposits [34].

Flexibility in choice of electrolyte composition, current density, and other conditions opens additional possibilities to engineer the microstructure of samples. Therefore, electrochemical deposition is one of the most promising methods for the synthesis of Bi films in light of their further applications. However, the influence of cathode current density during deposition on Bi films structure and especially crystalline texture is not fully understood yet.

The goal of this work was to investigate the influence of electrochemical deposition conditions of $\mathrm{Bi}$ films on their structure, microstructure, and electronic properties to explore the possibility of synthesizing high-quality polycrystalline samples with characteristics comparable to single-crystalline ones.

\section{Materials and methods}

\subsection{Samples preparation}

The electrodeposition of Bi films was performed using the following electrolyte composition (in moles/liter): $\mathrm{Bi}\left(\mathrm{ClO}_{4}\right)_{3}-0.51$, $\mathrm{HClO}_{4}-3$. Bismuth anodes used for electrodeposition, were prepared from $\mathrm{Bi}$ (97.5\%) and $\mathrm{Pb}$ (2.5\%). Electrodeposition was carried out in galvanostatic mode (constant current). The temperature during experiments lied in the $18-20^{\circ} \mathrm{C}$ range. The electrolyte had been continuously mixed at 750 rounds/min with magnetic stirrer IKA C-MAG HS. During experiments, three cathodic current densities (j) were used: $0.18,2.30$, and $70.0 \mathrm{~mA} / \mathrm{cm}^{2}$. The thickness of the $\mathrm{Bi}$ films was approximately $60 \mu \mathrm{m}$.

\subsection{Methods of investigation}

The thickness of films was controlled by the gravimetrical method using Ohaus AR 2140 balance (precision up to $1 \cdot 10^{-4} \mathrm{~g}$ ) and verified by scanning electron microscopy (SEM) cross-section images. The annealing of Bi films was performed in He gas atmosphere at $(267 \pm 1){ }^{\circ} \mathrm{C}$ for $5 \mathrm{~h}$ using the OWEN PM-10 oven.

The structure and morphology of samples were studied using X-ray diffraction analysis (XRD) and SEM. X-ray diffractograms were measured using monochromatic $\mathrm{Cu}-\mathrm{K} \alpha$ radiation with the PanAnalytical Empyrean diffractometer. SEM images were obtained in secondary electrons regime using LEO 1455VP Oxford Instruments SEM with $20 \mathrm{kV}$ accelerating voltage.

Resistivity, magnetoresistance, and Hall coefficient were measured in the 5-300 $\mathrm{K}$ temperature range under magnetic fields up to 8 T. All measurements were performed on Cryogen Free Measurement System from Cryogenic Ltd, London. Before electrical measurements, the Bi films were separated from $\mathrm{Cu}$ substrate and cut to uniform rectangles with sizes of $8 \times 3 \mathrm{~mm}^{2}$. Geometrical parameters were measured with optical microscope MPB-2 using a collimator ruler, which gives a $0.01 \mathrm{~mm}$ error. The film thicknesses were estimated on chips using SEM measurements. All samples were cleaned in a Sonorex ultrasonic bath just before soldering the contacts. The sample was connected to the contact pad using indium electric probes deposited with an ultrasonic soldering device. Six electric contacts were prepared on each sample: 2 current and 2 potential for 4-point probe resistivity measurements and 2 potential for the Hall voltage measurements. All measurements were made on direct current $\left(10^{-4}\right.$ A) with a Keithley Sub-Femtoamp RemoteSourceMeter SMU Instrument 6430 with an error of $0.05 \%$ or less. Voltages on potential probes were measured with $0.01 \%$ error or less using Keithley 2182A Nanovoltmeter.

The contact pad was located in a hermitized cell with He atmosphere with temperature and magnetic field sensors. The cell was inserted into a superconducting solenoid. The temperature was regulated by the flow of $\mathrm{He}$ and special electrical heaters inside the cell. The magnetic field was always perpendicular to the current direction. During Hall measurements, it is necessary to consider the influence of arising galvanomagnetic and thermomagnetic effects that otherwise can introduce significant errors. Besides, Hall contacts may not be equipotential before measurement starts. Therefore, the voltage $U_{H C}$ measured on Hall contacts is given by the relation

$U_{H C}=U_{H}+U_{N}+U_{E}+U_{R L}+U_{I R}$,

where $U_{H}$ is a true voltage due to the Hall effect,

$U_{N}$ - appears due to Nernst effect,

$U_{E}$ and $U_{R L}$ are related to Ettingshausen and Righi-Leduc effects,

$U_{I R}$ is the actual potential difference between Hall contacts in the absence of a magnetic field due to the non-equipotentiality of Hall contacts. 
The sign of each contribution is defined by signs of the current and magnetic field. There are four possible combinations of signals due to changes in the current $I$ and magnetic field $B$ directions:

$$
\begin{aligned}
& B+, I+: U_{H C}^{++}=U_{H}+U_{N}+U_{E}+U_{R L}+U_{I R} \\
& B+, I-: U_{H C}^{+-}=-U_{H}+U_{N}-U_{E}+U_{R L}-U_{I R} \\
& B-, I+: U_{H C}^{-+}=-U_{H}-U_{N}-U_{E}-U_{R L}+U_{I R} \\
& B-, I+: U_{H C}^{--}=U_{H}-U_{N}+U_{E}-U_{R L}-U_{I R} .
\end{aligned}
$$

From the equations above, it can be found that:

$U_{H}+U_{E}=\left(U_{H C}^{++}+U_{H C}^{+-}+U_{H C}^{-+}+U_{H C}^{--}\right) / 4$.

Taking into account that $U_{H}$ is usually much larger than $U_{E}$, it can be rewritten as

$U_{H}=\left(U_{H C}^{++}+U_{H C}^{+-}+U_{H C}^{-+}+U_{H C}^{--}\right) / 4$

The error in resistivity (and other specific values) was mainly defined by the sizes of indium electric contacts and was equal to or less than $5-7 \%$. According to our estimates, the reproducibility of directly measured (and non-specific) characteristics like potential differences or relative magnetoresistance was very good, and the error was less than $0.1 \%$.

\section{Results and discussion}

\subsection{Electrodeposition kinetics}

Cathodic polarization curves (PC) $\lg I(E)$ for the Bi films electrodeposition under various synthesis conditions are shown in Fig. 1. It can be seen that stirring of the electrolyte has practically no effect on the cathodic polarization curve dynamics down to $-0.11 \mathrm{~V}$. The electrodeposition of dense and flexible polycrystalline Bi films proceeds in a kinetically limited mode up to $0.01 \mathrm{~V}$ (Fig. 1, curves 1 and 2 , highlighted sections I, II). Then, in the potential range from 0.01 to $-0.14 \mathrm{~V}$, Bi electrodeposition occurs in a mixed diffusion-kinetic mode (Fig. 1, curves 1 and 2, section III).

In the potential range from -0.14 to $-0.35 \mathrm{~V}$ without stirring of the electrolyte, a diffusion plateau is observed, and the electrodeposition process proceeds in a diffusion-controlled mode (Fig. 1, curve 1 , section IV). A further shift of the polarization curve to the region of negative potentials (Fig. 1, curves 1 , section $\mathrm{V}$ ) leads to the formation on the electrode surface of a loose powdery deposit of dark gray color, which can be easily removed from the surface mechanically. The microstructure of Bi films varies from dense and compact to loose dendritic. Apparently, the formation of loose

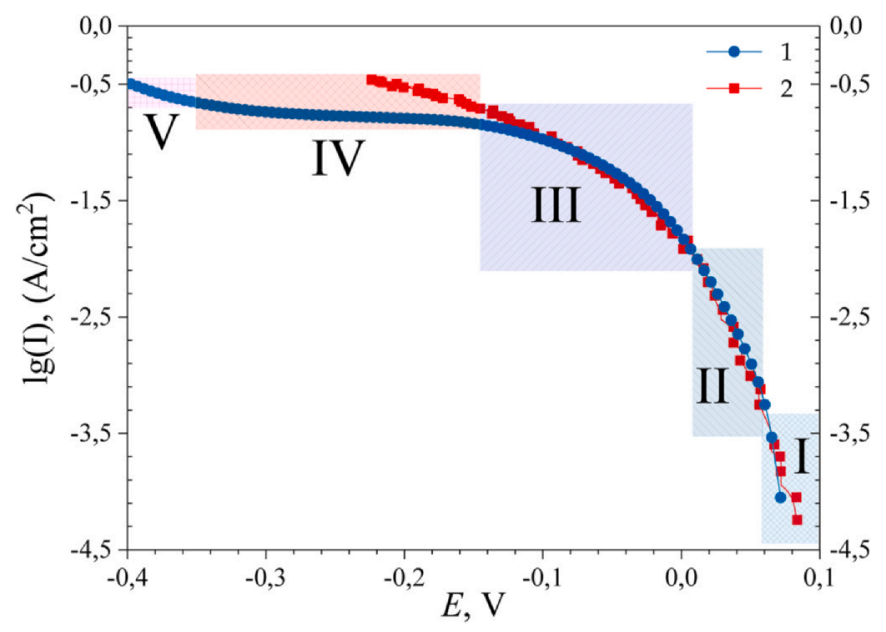

Fig. 1. Bi electrodeposition polarization curves without (1) and with (2) stirring of electrolyte. powdery Bi deposits can be associated with changes in the electrocrystallization mechanism and the limiting stage of the dischargeionization. Thus, the kinetically limited region of the Bi ions discharge from which it is possible to obtain Bi films with satisfactory quality is of greatest interest. There are three different ranges of current densities, which can be referred to as I, II, and III sections (Fig. 1). At low values of cathode polarization, the Tafel slope of the curve is $7.8 \mathrm{mV} /$ decade (section I). However, then the discharge of $\mathrm{Bi}$ ions occurs with a much higher Tafel slope in section II $(55.1 \mathrm{mV} /$ decade). An enhancement of the dependence of the current density on the potential and the difficulty of the discharge of $\mathrm{Bi}$ ions are observed in this case. This may be due to an increase in the adsorption of impurities in the electrolyte to nearby electrodes. Section III corresponds to a mixed diffusion-kinetic mode which is characterized by deposition of loose dendritic films. It can be assumed that, depending on the applied potential, the discharge process of $\mathrm{Bi}$ ions can proceed through various mechanisms and lead to the $\mathrm{Bi}$ films deposition with different structures and properties. To confirm this assumption, we chose different values of current density $(0.18$, 2.3 , and $70.0 \mathrm{~mA} / \mathrm{cm}^{2}$ ), which corresponded to polarization curves with different Tafel slopes and allowed us to obtain the samples with satisfactory quality (I, II, III sections).

\subsection{Crystal structure}

X-ray diffraction patterns have shown that all the studied Bi films had crystalline rhombohedral lattice (Fig. 2), as was expected [41,42]. The peaks in Fig. 2 are narrow, which indicates the large size of the coherence-scattering area and, therefore, the high structural quality of samples [43]. It has been shown that the films synthesized under a current density of 0.18 and $2.30 \mathrm{~mA} / \mathrm{cm}^{2}$ have an evident texture with the (012) preferred orientation of the crystallographic plane parallel to the substrate (Fig. 2, a,b). The crystalline texture is purest in samples synthesized under $j=0.18 \mathrm{~mA} / \mathrm{cm}^{2}$, which almost shown no reflexes from the other crystallographic planes (Fig. 2, a).

Texture coefficients $T_{c(h k l)}$ [44] were calculated to quantify the contribution of different preferred grain orientations:

$T_{C(h k l)}=\frac{I_{(h k l)} / I_{0(h k l)}}{\frac{1}{N}\left(\sum_{N} I_{(h k l)} / I_{0(h k l)}\right)}$,

where $h k l$ are indices of the corresponding plane, $I_{(h k l)}$ is the measured intensity of peak, $I_{O(h k l)}$ is relative intensity given in standard powder diffraction data, $N$ - is the number of clear peaks.

As can be seen from Table 1, the texture coefficients of all planes change monotonically with an increase in the cathodic current density during synthesis. The increase of cathode current density up to $2.30 \mathrm{~mA} / \mathrm{cm}^{2}$ leads to the growth of intensity of the reflexes that are attributed to the other grain orientations (Fig. 2b). The further increase of cathode current density to $j=70.0 \mathrm{~mA} / \mathrm{cm}^{2}$ leads to a change of the preferred orientation from (012) to (110), as shown in Fig. 2, c. Samples are more isotropic as intensities of the reflexes from different planes become comparable.

The weakening of Bi films' growth texture with the increase of the cathode current density may be related to cathode polarization that leads to non-equilibrium crystallization. The change in dominating texture of Bi film synthesized under $j=70.0 \mathrm{~mA} / \mathrm{cm}^{2}$ probably is attributed to different adsorption of atomic hydrogen and beginning of electrochemical reaction of hydrogen ions reduction: such a high cathode current density causes the reduction of $\mathrm{Bi}^{3+}$ in the diffusion-limited mode [34].

\subsection{Surface morphology}

The results of the SEM investigation showed that samples synthesized under a current density of 0.18 and $2.30 \mathrm{~mA} / \mathrm{cm}^{2}$ have a 


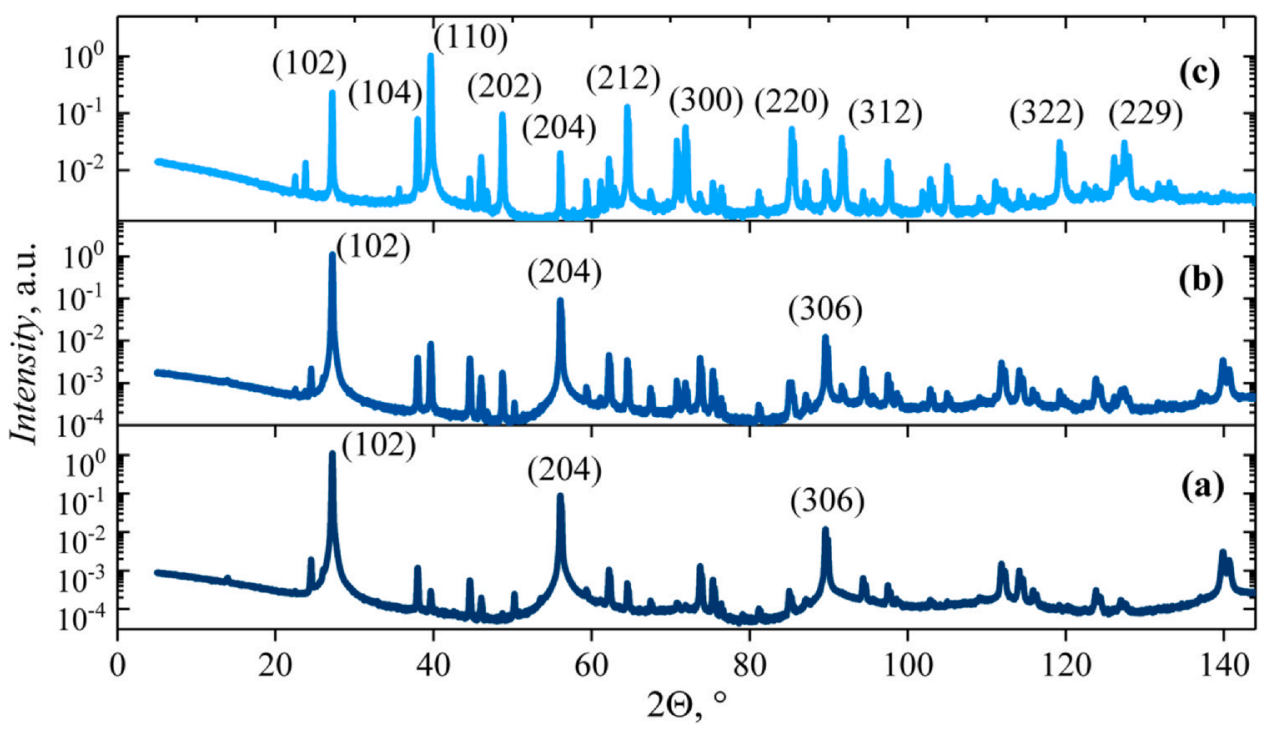

Fig. 2. X-Ray diffractograms for Bi films synthesized under various cathode currents: (a) $j=0.18 \mathrm{~mA} / \mathrm{cm}^{2}$, (b) $j=2.30 \mathrm{~mA} / \mathrm{cm}^{2},(\mathrm{c}) j=70.0 \mathrm{~mA} / \mathrm{cm}^{2}$.

Table 1

Texture coefficients.

\begin{tabular}{|c|c|c|c|c|c|c|c|c|c|c|}
\hline \multirow{2}{*}{$\begin{array}{l}\text { Cathodic current used for sample } \\
\text { deposition, } \mathrm{mA} / \mathrm{cm}^{2}\end{array}$} & \multicolumn{10}{|c|}{ Texture coefficient } \\
\hline & $T_{\mathrm{c}(102)}$ & $T_{\mathrm{c}(104)}$ & $T_{\mathrm{c}(110)}$ & $T_{\mathrm{c}(202)}$ & $T_{\mathrm{c}(204)}$ & $T_{\mathrm{c}(212)}$ & $T_{\mathrm{c}(300)}$ & $T_{\mathrm{c}(220)}$ & $T_{\mathrm{c}(312)}$ & $T_{\mathrm{c}(306)}$ \\
\hline 0.18 & 5.0 & 0.014 & 0.0033 & $1 \cdot 10^{-4}$ & 3.0 & 0.010 & 0.058 & 0.024 & 0.024 & 0.95 \\
\hline 2.30 & 4.7 & 0.044 & 0.87 & 0.08 & 2.9 & 0.071 & 0.055 & 0.093 & 0.092 & 0.93 \\
\hline 70.0 & 0.30 & 0.27 & 3.3 & 0.55 & 0.19 & 0.82 & 0.95 & 1.5 & 0.66 & $1 \cdot 10^{-4}$ \\
\hline
\end{tabular}

dense pyramidal structure with an average grain size of $12-20 \mu \mathrm{m}$ (Fig. 3, a) and 10-12 $\mu \mathrm{m}$ (Fig. 3, b), respectively. Bi films electrodeposited under $70.0 \mathrm{~mA} / \mathrm{cm}^{2}$ are porous with elongated lamellar grains of $(1-2) \mu \mathrm{m}$ width and of $(10-12) \mu \mathrm{m}$ length (Fig. 3, c). It should be noted that the increase of electrodeposition current density resulted in both the decrease in the grain size and changing of their shape. Such behavior of Bi grain sizes is odd enough since the opposite tendency is observed in most studies [45-47]. Obviously, this is because the fact that the discharge process of $\mathrm{Bi}$ ions is multistage and includes the sequential addition of three electrons. Accordingly, depending on the applied current density, the discharge mechanism can also change. The ions present in the electrolyte can influence the electrodeposition process. The current efficiency for $\mathrm{Bi}$ in this perchlorate electrolyte is $100 \%$ in most cases, so hydrogen cannot have this effect on Bi (especially at the used current densities values). It can also be associated with the impurities adsorption on the Bi grain faces. The more impurities in the electrolyte lead to the larger the grain size. Note that the impurity concentration decreases with current density rising.

Another version of the explanation for the mechanism of grain size changing can be a decrease in the concentration of $\mathrm{Bi}^{3+}$ ions in the cathode layer, which leads to over speed of the nucleation rate of crystallization centers over the faces growth rate.

\subsection{Electronic properties}

Bi films synthesized under 0.18 and $2.30 \mathrm{~mA} / \mathrm{cm}^{2}$ current density were successfully connected to setup probes using indium for electric contacts with excellent reproducibility of measurement results. However, samples fabricated under $70.0 \mathrm{~mA} / \mathrm{cm}^{2}$ turned to be fragile and easily cracked and crumbled by the ultrasonic soldering device, so we decided not to rely on their data.

The electrical resistivity $\rho$ of $\mathrm{Bi}$ samples synthesized under $0.18 \mathrm{~mA} / \mathrm{cm}^{2}$ decreases with temperature $T$ (curve 1 in Fig. 4), while the resistivity of samples synthesized under $2.30 \mathrm{~mA} / \mathrm{cm}^{2}$ increases (curve 2 in Fig. 4). The resistivity lowers after the annealing at $261 \mathrm{~K}$ and demonstrates linear growth with the temperature (curves $1 \mathrm{a}$ and 2a in Fig. 4).

Relative magnetoresistance is defined as $\Delta \rho(B) / \rho(0)$, where $\Delta \rho(B)=\rho(B)-\rho(0)$ and $\rho(B)$ is resistivity in magnetic field $B$. Temperature dependences of magnetoresistance in $B=8 \mathrm{~T}$ are given in Fig. 5 and show that $\Delta \rho(B)$ monotonously decreases with the temperature. The effect of annealing is most noticeable at low temperatures (1a and 2a in Fig. 5), where annealing increases the magnetoresistance by an order of magnitude compared to as-deposited samples.

The relative magnetoresistance of $\mathrm{Bi}$ films monotonously increases with the magnetic field (Fig. 6) and decreases with temperature, which is typical for Lorentz magnetoresistance mechanism when the $\Delta \rho(B) / \rho(0)$ is proportional to $B^{2}$ in the small field limit $(B \rightarrow$ 0) $[48,49]$.

In the case of the Lorentz mechanism, the magnetoresistance effect is known to be stronger for high-mobility carriers [50,51]. Lorentz magnetoresistance in $\mathrm{Bi}$ can be expressed through the characteristics of charge carriers [52-54]:

$\frac{\Delta \rho(B)}{\rho(0)}=\frac{9 \pi}{16}\left(\frac{(3 r+3 / 2) !}{((r+3 / 2) !)^{3}} \frac{p \mu_{p}^{3}+n \mu_{n}^{3}}{p \mu_{p}+n \mu_{n}}-\left(\frac{(2 r+3 / 2) !}{((r+3 / 2) !)^{2}} \frac{p \mu_{p}^{2}-n \mu_{n}^{2}}{p \mu_{p}+n \mu_{n}}\right)^{2}\right) B^{2}$,

where $R_{\mathrm{H}}$ is the Hall coefficient, $r$ is the scattering factor [48], $r_{H}$ is the Hall factor, $n, p$ and $\mu_{n}, \mu_{p}$ are concentrations and mobilities of electrons and holes, respectively.

Eq. (6) indicates that magnetoresistance strongly depends on mobility of carriers. In samples deposited under $j=2.30 \mathrm{~mA} / \mathrm{cm}^{2}$ grains are smaller (Fig. $3 \mathrm{~b}$ ), which leads to more intensive scattering of electrons on grain boundaries. This explains smaller mobilities 


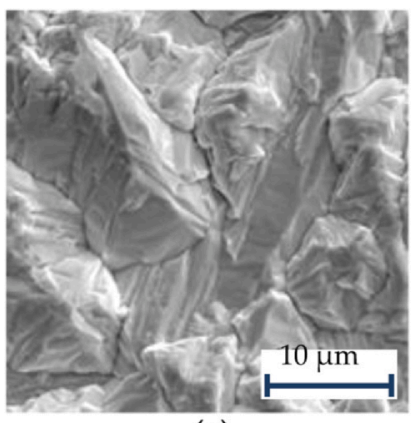

(a)

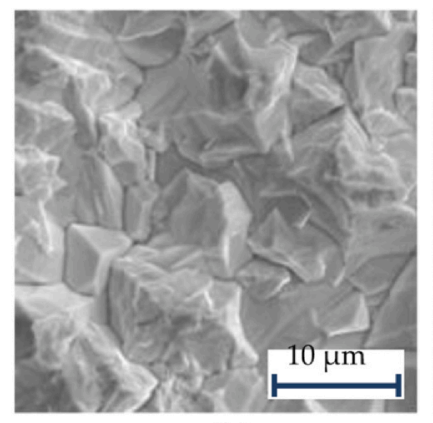

(b)

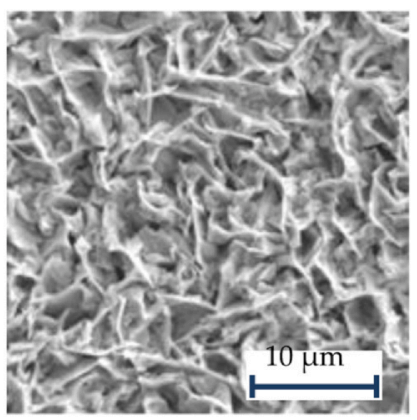

(c)

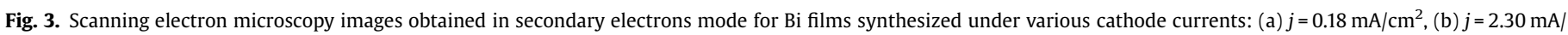
$\mathrm{cm}^{2}$, (c) $j=70.0 \mathrm{~mA} / \mathrm{cm}^{2}$.

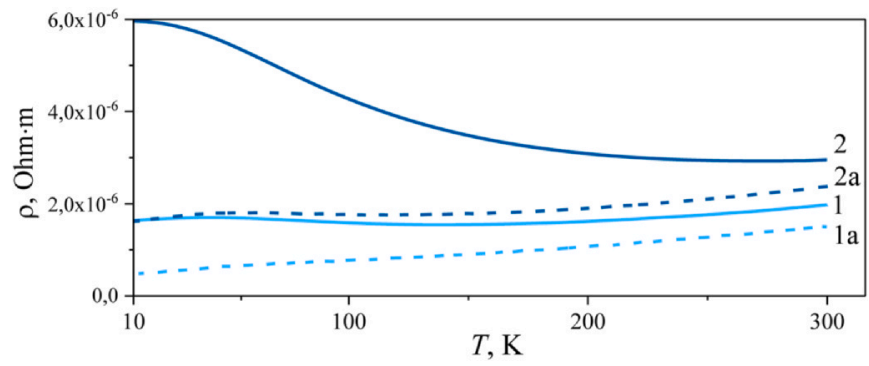

Fig. 4. Temperature dependence of electrical resistivity for as-deposited and annealed Bi films synthesized under various cathode currents (annealed samples dependencies marked with "a"): $1-j=0.18 \mathrm{~mA} / \mathrm{cm}^{2}, 2-j=2.30 \mathrm{~mA} / \mathrm{cm}^{2}$.

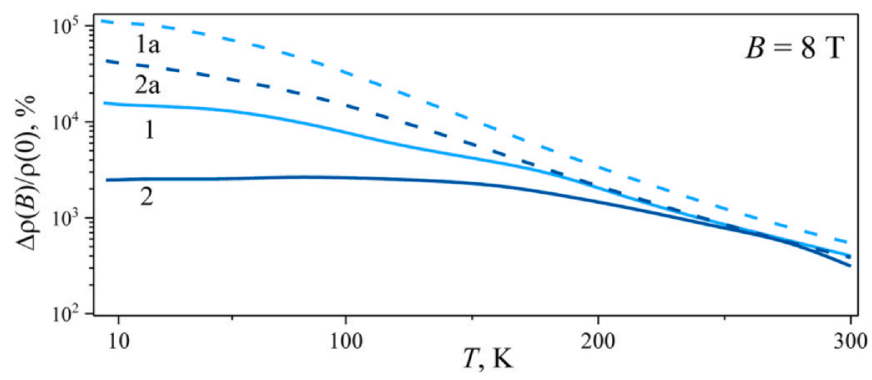

Fig. 5. Temperature dependence of relative magnetoresistance at $8 \mathrm{~T}$ for as-deposited and annealed Bi films synthesized under various cathode currents (annealed samples dependencies marked with "a"): $1-j=0.18 \mathrm{~mA} / \mathrm{cm}^{2}, 2-j=2.30 \mathrm{~mA} / \mathrm{cm}^{2}$.

and lower magnetoresistance in the sample with smaller grains (Fig. 6c and Table 2).

Field dependencies of Hall coefficient for Bi films synthesized under cathode current $j=0.18 \mathrm{~mA} / \mathrm{cm}^{2}$ and for $j=2.30 \mathrm{~mA} / \mathrm{cm}^{2}$ are given in Fig. 7.

Hall coefficient in all samples is negative, which indicates that the majority carriers are electrons. The absolute value of the Hall coefficient increases with the temperature in all samples that indicates the increase of carriers' concentration.

In recent years a new family of methods was developed called Quantitative Mobility Spectrum Analysis (QMSA) [55-57]. It uses data in all available ranges of magnetic fields and requires minimum external input parameters for the computational procedure. For this, it is necessary to calculate the components of the magnetoconductivity tensor: $\sigma_{x x}(B)=\frac{\rho(B)}{\rho(B)^{2}+R_{H}^{2} B^{2}}$,

$\sigma_{x y}(B)=\frac{R_{H}(B) \cdot B}{\rho(B)^{2}+R_{H}^{2} B^{2}}$,

where $\sigma_{x x}$ is magnetoconductivity and $\sigma_{x y}$ is Hall conductivity. The underlying physics is based on the McClure's solution of Boltzmann equation for electrons in magnetic field [58], which connects magnetoconductivity, charge carriers concentration $n$ and mean mobility $\langle\mu\rangle$ :

$\sigma_{x x}(B)=\frac{q n\langle\mu\rangle}{1+\langle\mu\rangle^{2} B^{2}}$

$\sigma_{x y}(B)=\frac{q n\langle\mu\rangle^{2} B}{1+\langle\mu\rangle^{2} B^{2}}$.

In the QMSA approach, $n$ is considered as a function of $\mu$, which reflects the actual distribution of carrier's over energy. Such an approach allows the precise evaluation of mobilities and concentrations in materials with several types of carriers. Instead of the average value $\langle\mu\rangle$, QMSA considers grid of mobility $\mu_{i}$. This leads to a discretized form of (11)-(12):

$\sigma_{x x}(B)=\sum_{i=1}^{M}\left(\frac{e n_{i} \mu_{i}}{1+\mu_{i}^{2} B^{2}}+\frac{e p_{i} \mu_{i}}{1+\mu_{i}^{2} B^{2}}\right)$,

$\sigma_{x y}(B)=\sum_{i=1}^{M}\left(\frac{e n_{i} \mu_{i}^{2} B}{1+\mu_{i}^{2} B^{2}}-\frac{e p_{i} \mu_{i}^{2} B}{1+\mu_{i}^{2} B^{2}}\right)$,

where $n_{i}$ and $p i$ are the concentration of electrons and holes that have mobility $\mu_{i}$, respectively.

The numerical procedure [59] is a simultaneous fitting Eqs. (11)-(12) to get the smallest deviation between the experimental data and $\sigma_{x x}(B), \sigma_{x y}(B)$ reconstructed from (11) and (12).

The experimental data and model based on the QMSA model are given in Fig. 8. As can be seen from Fig. 8, they are in agreement.

From numerical values of mobility and concentration obtained from fitting, it is possible to compute averaged charge carrier concentrations. Temperature dependences of concentrations and mobilities are given in Fig. 9.

In all samples, the concentration monotonically increases with temperature (Fig. 9a). The concentrations of electrons and holes are similar as expected from intrinsic material (Eq. (11)). Averaged temperature dependence of carriers' concentration with two standard deviation error bar is given in Fig. 9a inset. Concentration 


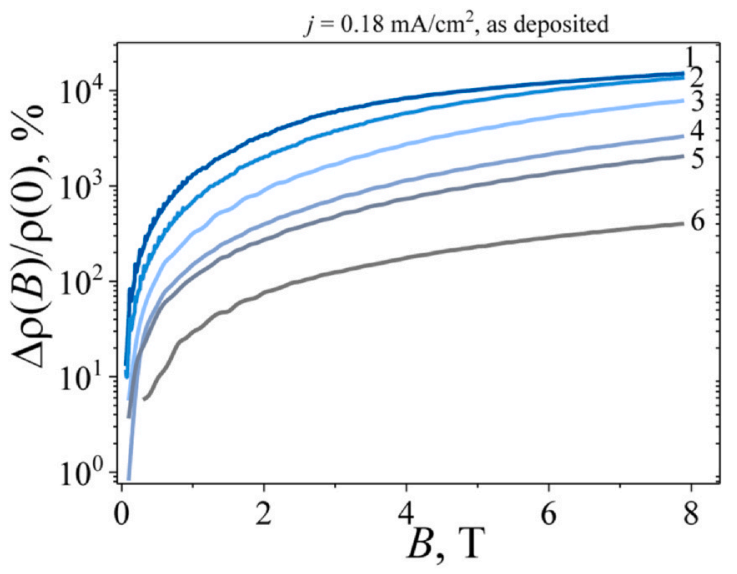

(a)

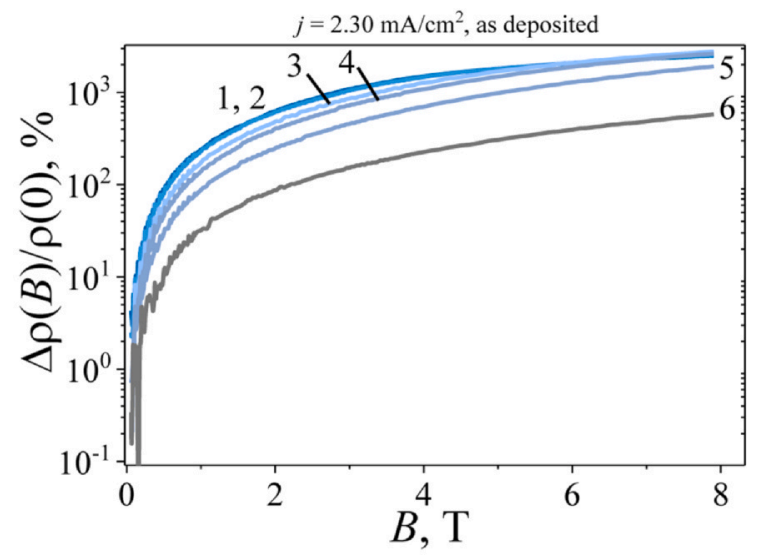

(c)

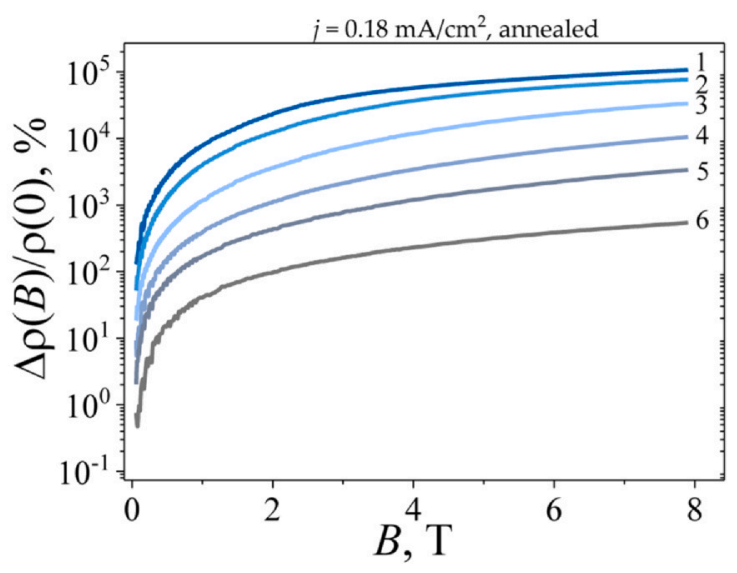

(b)

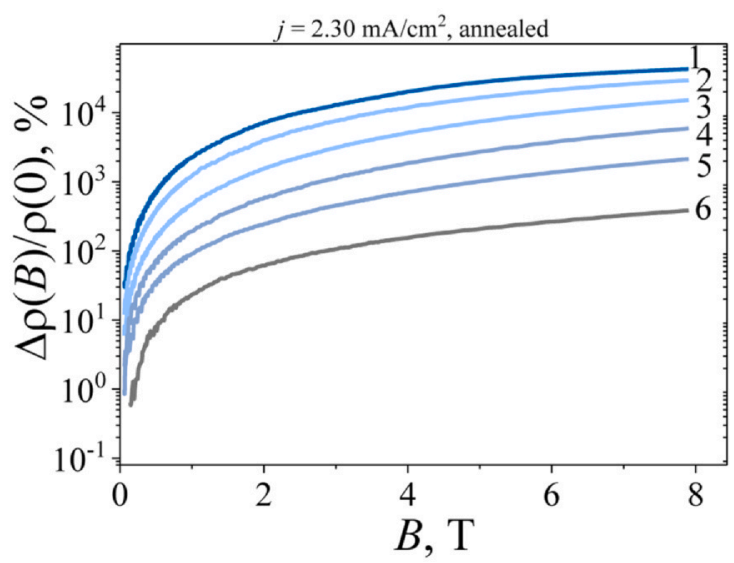

(d)

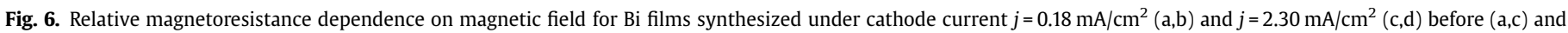
after (b,d) annealing for different temperatures: (1) - $5 \mathrm{~K},(2)-50 \mathrm{~K},(3)-100 \mathrm{~K},(4)-150 \mathrm{~K},(5)-200 \mathrm{~K},(6)-300 \mathrm{~K}$.

Table 2

Magnetoresistance of Bi films at $B=8 \mathrm{~T}$ measured at $T=5 \mathrm{~K}$ and $T=300 \mathrm{~K}$.

\begin{tabular}{llll}
\hline $\begin{array}{l}\text { Cathode current } \\
\text { density during } \\
\text { deposition, } \\
\mathbf{m A} / \mathbf{c m}^{\mathbf{2}}\end{array}$ & $\begin{array}{l}\text { Temperature of } \\
\text { electronic } \\
\text { measurements, } \mathbf{K}\end{array}$ & $\begin{array}{l}\text { Relative } \\
\text { magnetoresistance, \% }\end{array}$ \\
\cline { 3 - 4 } & & $\begin{array}{l}\text { As- } \\
\text { deposited }\end{array}$ & Annealed \\
\hline 0.18 & 5 & $1.6 \cdot 10^{4}$ & $1.1 \cdot 10^{5}$ \\
2.30 & 300 & $4.0 \cdot 10^{2}$ & $5.510^{2}$ \\
& 5 & $2.8 \cdot 10^{3}$ & $4.1 \cdot 10^{4}$ \\
& 300 & $3.1 \cdot 10^{2}$ & $3.9 \cdot 10^{2}$ \\
\hline
\end{tabular}

values are in good agreement with the literature [48,49], which indicates the high quality of bismuth samples and shows no traces of unplanned doping.

Mobility of charge carriers lowers with temperature (Fig. 9b). The values of carriers' mobility correlate with grain size and magnetoresistance: samples with larger grains show higher mobility. So, electrons in the sample deposited under cathode current $j=0.18 \mathrm{~mA} /$ $\mathrm{cm}^{2}$ mobility is half an order higher than samples deposited under $j=2.30 \mathrm{~mA} / \mathrm{cm}^{2}$ (see 1 and 3 in Fig. 9b). Annealing also increases the mobility of carriers. The mobility of charge carriers in the studied samples is slightly lower than that known from the literature for high-quality epitaxial films [60,61].

The difference in mobilities in samples can be attributed to the different role of scattering on grain boundaries. This can be explained from Matthiessen rule for effective mobility $\mu_{\text {eff }}$ of carriers [48]: $\mu_{\text {eff }}=\left(\frac{1}{\mu_{a}}+\frac{1}{\mu_{b}}\right)^{-1}$,

where $\mu_{a}$ and $\mu_{b}$ are two contributions to the mobility related to different scattering mechanisms.

In the case of undoped polycrystalline bismuth, $\mu_{a}$ is the mobility limited by the scattering on phonons, and $\mu_{b}$ is the mobility limited by the scattering on structural defects, i.e., grain boundaries. Scattering by phonons occurs in approximately the same way in all samples since we do not expect a change of the phonon spectrum for the obtained grain size. Therefore, the main difference is related to $\mu_{b}$. Temperature dependence of grain-scattering contribution to electron mobility $\mu_{b n}$ and hole mobility $\mu_{b p}$ are given by

$\mu_{b n}(T)=\frac{e \lambda_{e}}{\sqrt{2 \zeta_{n}(T) m_{n}^{*}}}\left(1+\frac{\zeta_{n}(T)}{E_{g}(T)}\right)^{-\frac{1}{2}}$,

$\mu_{b p}(T)=\frac{e \lambda_{h}}{\sqrt{2 \zeta_{p}(T) m_{p}^{*}}}$

where $m_{n}{ }^{*}, m_{p}{ }^{*}$ - effective masses of electron and hole, $\xi_{n}, \xi_{p}$ - Fermi level counted from the conduction or valence band extrema, $E_{g}-$ bandgap, $\lambda_{n}, \lambda_{p}$ - mean free path of carriers due to grain scattering.

The mean free path due to grain scattering is the same as the grain diameter and doesn't depend on temperature, so $\mu_{b}$ contribution to resulting mobility (see Eq. (13)) will be similar in all temperature range. In opposite, the mean free path due to scattering 


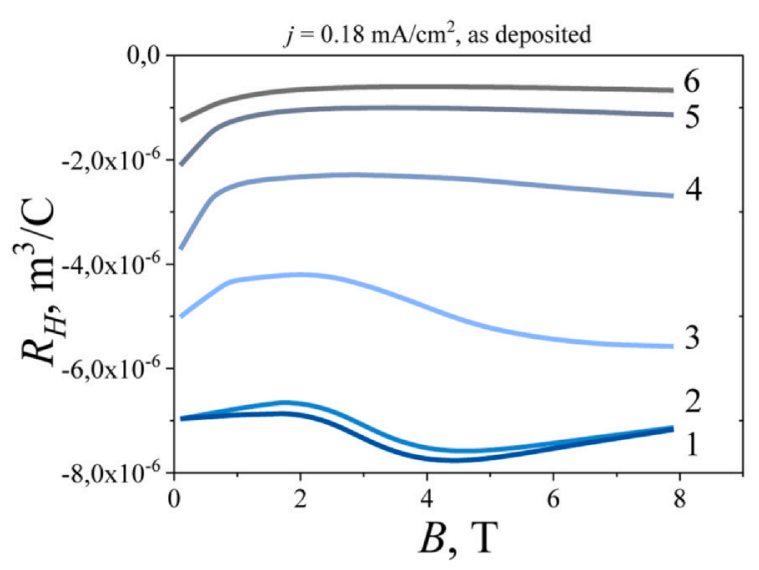

(a)

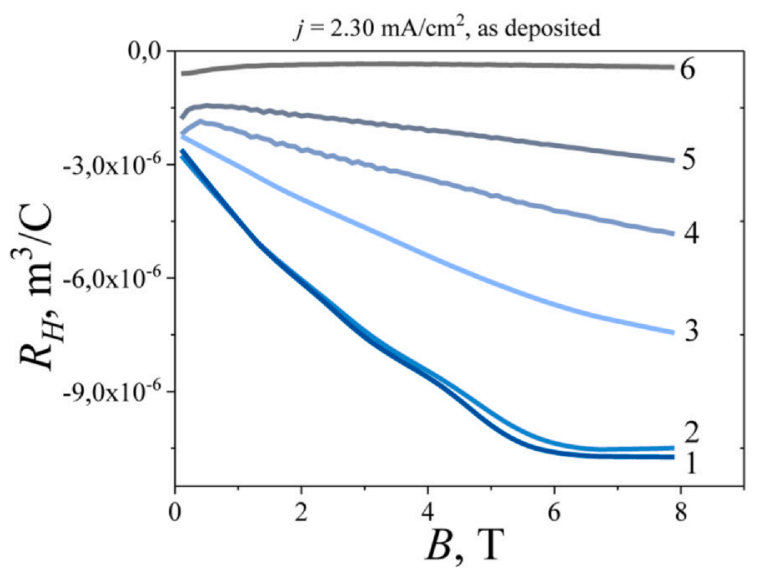

(c)

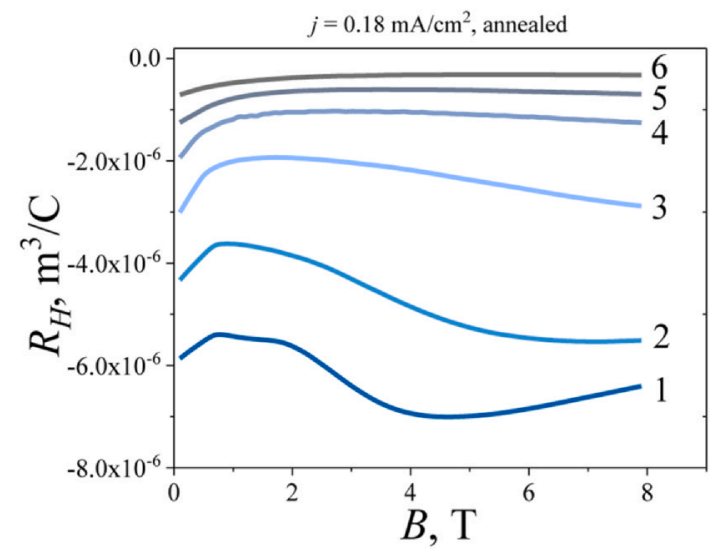

(b)

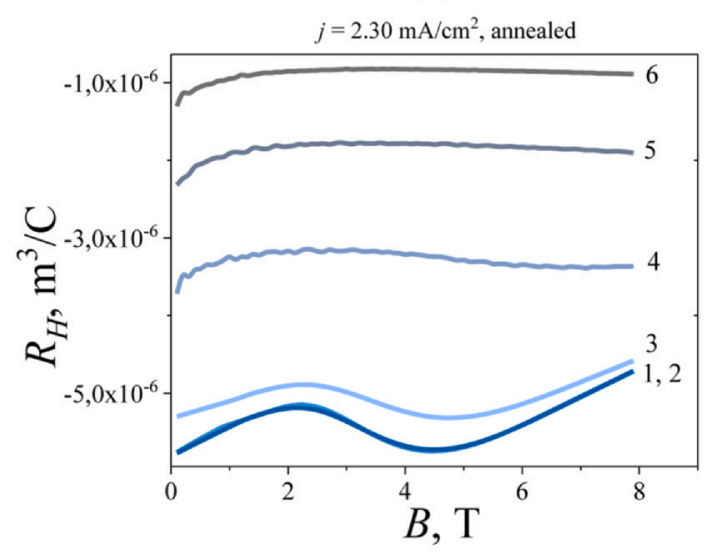

(d)

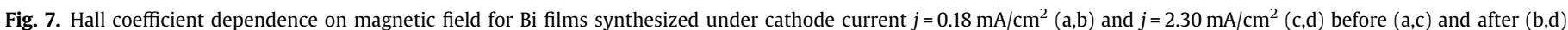
annealing for different temperatures: (1) - $5 \mathrm{~K},(2)-50 \mathrm{~K},(3)-100 \mathrm{~K},(4)-150 \mathrm{~K},(5)-200 \mathrm{~K},(6)-300 \mathrm{~K}$.

on phonons rapidly decreases with temperature due to an increase of phonons concentration. It follows from Eq. (13) that when $\mu_{a}$ is of the same magnitude or lower than $\mu_{b}$, the latter will not significantly influence the resulting mobility $\mu_{\text {eff. }}$.

At high temperatures mean free path is presumably limited by phonon scattering; therefore, we observe close values for mobilities of carriers in all samples (Fig. 9b). However, at low temperatures scattering on grain boundary dominates, which explains higher mobility in samples with larger grains. Annealing usually leads to the enlargement of grains and, as a rule, reduces electron scattering on grain boundaries and point defects. Therefore, the low-temperature mobility of electrons increases, as we can observe in Fig. 9 and Table 2.

This allows us to explain different temperature dependences of resistivity given in Fig. 4. In annealed samples resistivity grows linearly with temperature (Fig. 4), while as-deposited samples show non-monotonous dependence with a minimum. Resistivity $\rho$ is defined as

$\rho=\sigma^{-1}=\left(e n \mu_{n}+e p \mu_{p}\right)^{-1}$,

where $\sigma$ is conductivity.

According to Eq. (16), the temperature dependence of resistivity is defined by the temperature dependence of concentrations $n, p$ and mobilities $\mu_{n}, \mu_{p}$. Concentration temperature dependence is similar for all the samples (Fig. 9a). The temperature dependence of mobility is different due to more enhanced scattering in as-deposited samples. As is seen from Fig. 9b, mobility in large-grained annealed samples decreases by an order of magnitude in the temperature range from 10 to $300 \mathrm{~K}$. Mobility in small-grained samples (curves 3 and 4 in Fig. 9b) only decreases two times in the same temperature range. Therefore, annealed samples show a linear, metal-like temperature dependence of resistivity due to strong temperature dependence of mobility. In contradiction, as-deposited samples are characterized by a temperature-independent scattering and weaker temperature dependence of mobility at low temperatures. Their more complicated temperature dependence of resistivity is a combination of comparable contributions of mobility and concentration dependences $[63,64]$.

It is important to note from the practical point of view that the magnetoresistance in annealed Bi films deposited under $j=0.18 \mathrm{~mA} /$ $\mathrm{cm}^{2}$ is the highest among the studied samples (Table 2) and is comparable to the magnetoresistance of single-crystalline samples or thick epitaxial films. The reported magnetoresistance in Bi singlecrystals is about $4 \cdot 10^{5}$ at $5 \mathrm{~K}$ under $B=9 \mathrm{~T}$ [2] whereas, for the annealed samples electrodeposited at $j=0.18 \mathrm{~mA} / \mathrm{cm}^{2}$, the magnetoresistance under $B=8 \mathrm{~T}$ value is about $1,1 \cdot 10^{5}$ at the same temperature (Fig. 6). For thick epitaxial films, the relative magnetoresistance reaches $10^{3}$ (about $10^{5} \%$ ) at $20 \mathrm{~K}$ under $8 \mathrm{~T}$ field [61], while in the annealed samples electrodeposited at $j=0.18 \mathrm{~mA} / \mathrm{cm}^{2}$ the magnetoresistance also reaches $10^{5} \%$ under similar conditions (Fig. 6). 


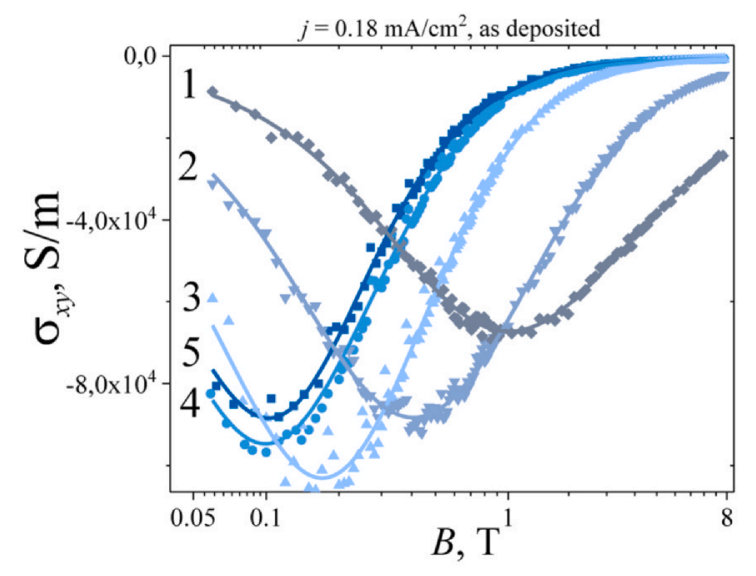

(a)

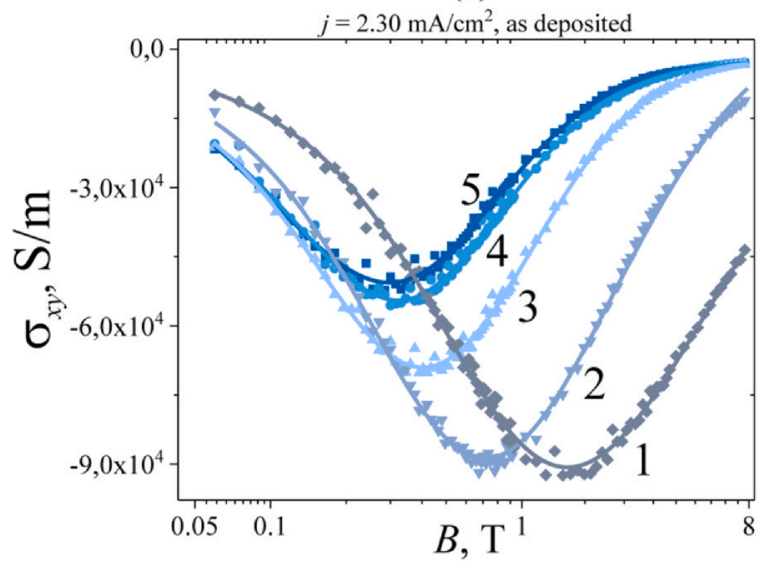

(c)

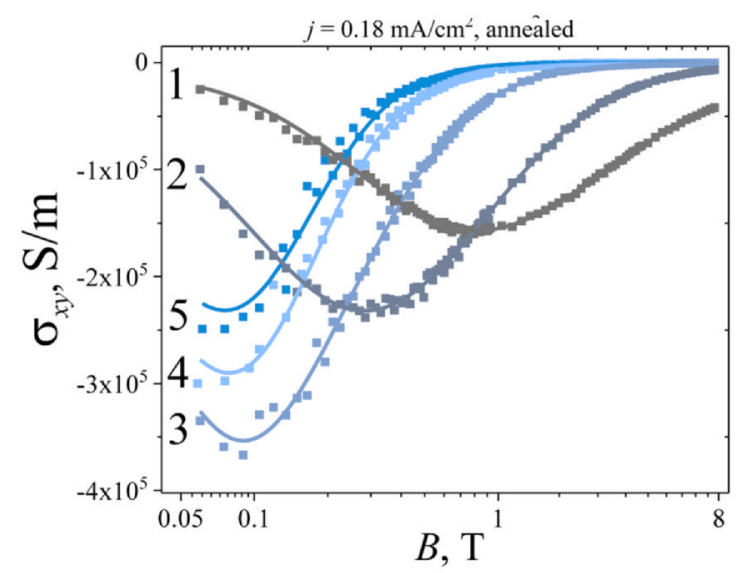

(b)

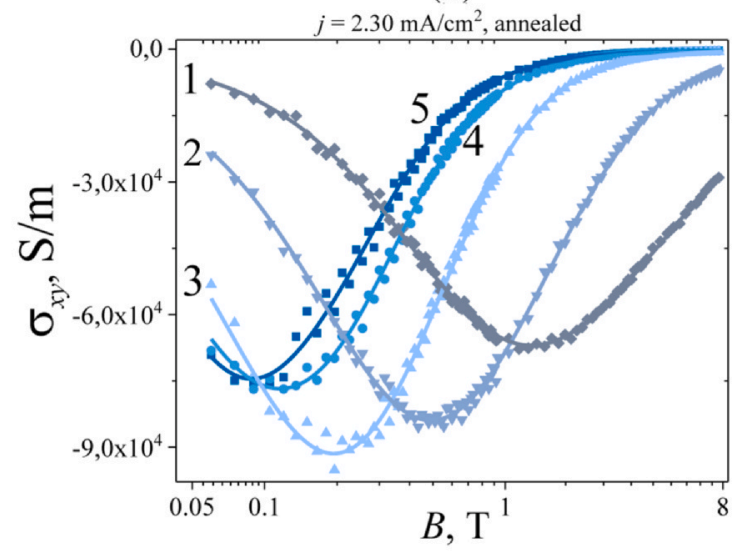

(d)

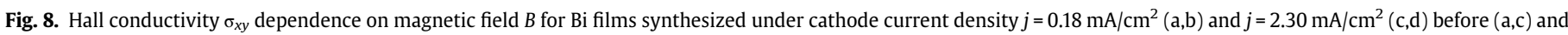
after (b,d) annealing for different temperatures: $1-300$ K, $2-200$ K, $3-100$ K, $4-50$ K, 5 - 25 K. Scatter: experimental data, solid lines: model.

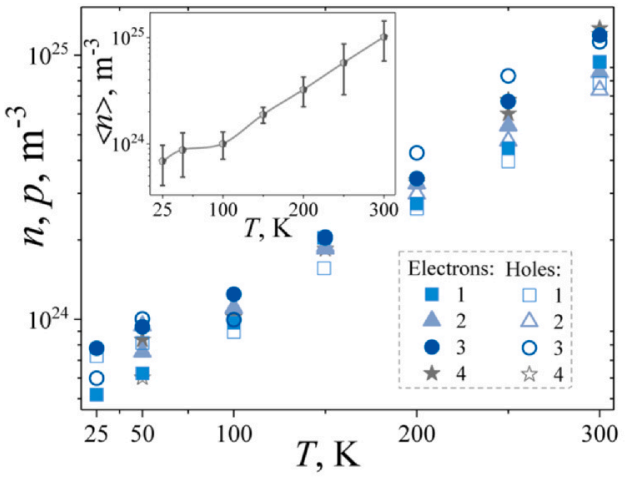

(a)

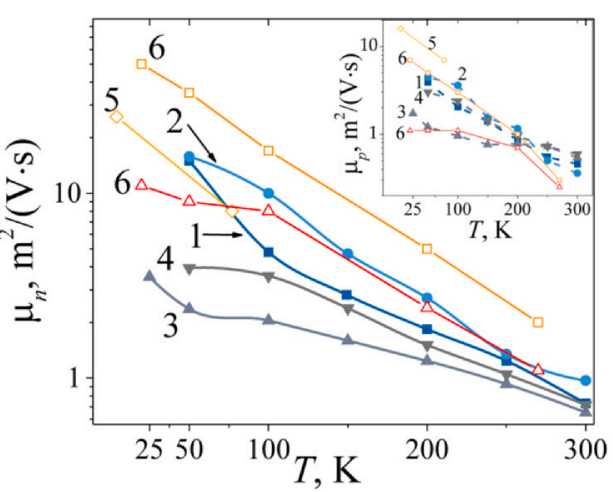

(b)

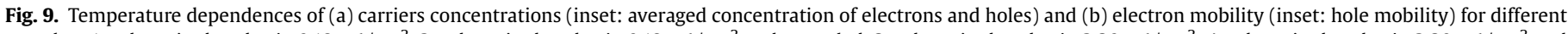

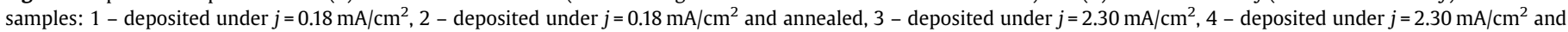
annealed, 5 and 6 - literature data for epitaxial films from [60] and [61] correspondingly.

\section{Conclusion}

In summary, we have revealed the correlation between the main morphological, structural, and electronic properties of Bi films deposited under different conditions using newly-developed perchlorate electrolyte. Deposition occurred under constant cathode current with higher speed $200 \mu \mathrm{m} / \mathrm{h}$ (while traditional nitrate electrolytes are limited by $12 \mu \mathrm{m} / \mathrm{h}$ ) resulted in dense coatings with a thickness of about $60 \mu \mathrm{m}$. It was shown that the increase of cathode current from $j=0.18 \mathrm{~mA} / \mathrm{cm}^{2}$ to $70.0 \mathrm{~mA} / \mathrm{cm}^{2}$ leads to the formation of more isotropic samples with less expressed texture and smaller grains.

In the samples deposited under $j=0.18 \mathrm{~mA} / \mathrm{cm}^{2}$, relative magnetoresistance under magnetic field $B=8 \mathrm{~T}$ at temperature $T=5 \mathrm{~K}$ increases up to $1,1 \cdot 10^{5}$ with the growth of grain sizes due to annealing being equal to magnetoresistance of single-crystals. The observed difference in magnetoresistance of samples deposited under currents $j=0.18 \mathrm{~mA} / \mathrm{cm}^{2}$ and $j=2.30 \mathrm{~mA} / \mathrm{cm}^{2}$ was explained 
by the significant role of scattering on grain boundaries and structural defects, which was confirmed by the temperature dependence of mobility.

From the practical point of view, the samples synthesized under $j=0.18 \mathrm{~mA} / \mathrm{cm}^{2}$ can be used as a cheaper alternative to single crystals for such applications as functional electrodeposited layers in multilayered films structures based on magnetic/diamagnetic materials. These multilayered film structures can be applied: $i$. for highly efficient DC and AC magnetic field shielding; ii. for magnetic field sensors and iii. spintronic devices. Samples synthesized under higher current densities are less similar to monocrystals but are more isotropic according to XRD analysis. Isotropic properties of the electrodeposited Bi films with comparable values to the single crystals open broad prospects for replacement of the Bi single crystals in functional devices by the films. This means that such material can be used in devices that will be technologically convenient and has a large advantage.

\section{CRediT authorship contribution statement}

Alexander Fedotov: Investigation (Conducting a research and investigation process, specifically performing the experiments, or data/evidence collection), Funding acquisition (Acquisition of the financial support for the project leading to this publication). Vladislav Shendyukov: Investigation (Conducting a research and investigation process, specifically performing the experiments, or data/evidence collection). Ludmila Tsybulskaya: Supervision (Oversight and leadership responsibility for the research activity planning and execution, including mentorship external to the core team). Sergey Perevoznikov: Investigation (Conducting a research and investigation process, specifically performing the experiments, or data/evidence collection). Mengge Dong: Investigation (Conducting a research and investigation process, specifically performing the experiments, or data/evidence collection). Xiangxin Xue: Data curation (Management activities to annotate (produce metadata), scrub data and maintain research data (including software code, where it is necessary for interpreting the data itself) for initial use and later reuse). Xiating Feng: Investigation (Conducting a research and investigation process, specifically performing the experiments, or data/evidence collection). M.I. Sayyed: Investigation (Conducting a research and investigation process, specifically performing the experiments, or data/evidence collection). Tatiana Zubar: Methodology (Development or design of methodology; creation of models), Formal analysis (Application of statistical, mathematical, computational, or other formal techniques to analyze or synthesize study data). Alex Trukhanov: Conceptualization (Ideas; formulation or evolution of overarching research goals and aims), Formal analysis (Application of statistical, mathematical, computational, or other formal techniques to analyze or synthesize study data). Daria Tishkevich: Investigation (Conducting a research and investigation process, specifically performing the experiments, or data/evidence collection), Funding acquisition (Acquisition of the financial support for the project leading to this publication).

\section{Declaration of Competing Interest}

The authors declare that they have no known competing financial interests or personal relationships that could have appeared to influence the work reported in this paper.

\section{Acknowledgments}

This research was funded by the Belarusian Republican Foundation for Fundamental Research, grant F16M-067 "Structure and magnetoresistive characteristics of $\mathrm{Bi}$ thin films" and by
International Innovation Center for Nanotechnology of the CIS (grant No. 21-114). The work was partially supported by the Fundamental Research Funds for the Central Universities, Postdoctoral Science Foundation of Northeastern University (20210207). We acknowledge the help of researcher Ivan Svito from the Energy Physics Department of Belarusian State University for his help in sample preparation and electric measurements.

\section{References}

[1] W. Ning, F. Kong, J. Hu, Y. Han, J. Yang, H. Du, Y. Zhang, M. Tian, La Crosse viral infection in hospitalized pediatric patients in Western North Carolina, Hosp. Pedia 2 (2012) 235-242, https://doi.org/10.1063/1.4978753

[2] F.Y. Yang, K. Liu, K. Hong, D.H. Reich, P.C. Searson, C.L. Chien, Large magnetoresistance of electrodeposited single-crystal bismuth thin films, Science $284(80)$ (1999) 1335-1337, https://doi.org/10.1126/science.284.5418.1335

[3] A. Sánchez-Calvo, M.C. Blanco-López, A. Costa-García, Paper-based working electrodes coated with mercury or bismuth films for heavy metals determination, Biosensors 10 (2020) 17-19, https://doi.org/10.3390/BIOS10050052

[4] A. Vorobjova, D. Tishkevich, D. Shimanovich, M. Zdorovets, A. Kozlovskiy, T. Zubar, D. Vinnik, M. Dong, S. Trukhanov, A. Trukhanov, V. Fedosyuk, Electrochemical behaviour of $\mathrm{Ti} / \mathrm{Al}_{2} \mathrm{O}_{3} / \mathrm{Ni}$ nanocomposite material in artificial physiological solution: Prospects for biomedical application, Nanomaterials. 10 (2020) 173, https://doi.org/10.3390/nano10010173

[5] V. Zavaleyev, J. Walkowicz, T. Kuznetsova, T. Zubar, The dependence of the structure and mechanical properties of thin ta-C coatings deposited using electromagnetic venetian blind plasma filter on their thickness. Thin Solid Films. 638 (2017) 153-158, https://doi.org/10.1016/j.tsf.2017.07.050

[6] B. Warcholinski, A. Gilewicz, A. Kuprin, G. Tolmachova, T. Ovcharenko, T. Kuznetsova, T. Zubar, A. Khudoley, S. Chizhik, Mechanical properties of Cr-O-N coatings deposited by cathodic arc evaporation, Vacuum. 156 (2018) 97-107, https://doi.org/10.1016/j.vacuum.2018.07.017

[7] R. Wang, H. Li, H. Sun, Bismuth: Environmental Pollution and Health Effects, 2nd ed., Elsevier Inc, 2019, https://doi.org/10.1016/B978-0-12-409548-9.11870-6

[8] F. Qin, R. Wang, G. Li, F. Tian, H. Zhao, R. Chen, Highly efficient photocatalytic reduction of $\mathrm{Cr}(\mathrm{VI})$ by bismuth hollow nanospheres, Catal. Commun. 42 (2013) 14-19, https://doi.org/10.1016/j.catcom.2013.07.039

[9] D. Ma, Y. Zhao, J. Zhao, Y. Li, Y. Lu, D. Zhao, Aqueous synthesis of hierarchical bismuth nanobundles with high catalytic activity to organic dyes, Superlattices Micro 83 (2015) 411-421, https://doi.org/10.1016/j.spmi.2015.03.052

[10] D. Ma, J. Zhao, Y. Zhao, X.L. Hao, Y. Lu, An easy synthesis of 1D bismuth nanostructures in acidic solution and their photocatalytic degradation of rhodamine $B$, Chem. Eng. J. 209 (2012) 273-279, https://doi.org/10.1016/j.cej.2012.08.021

[11] F. Dong, T. Xiong, Y. Sun, Z. Zhao, Y. Zhou, X. Feng, Zh Wu, A semimetal bismuth element as a direct plasmonic photocatalyst, Chem. Commun. 50 (2014) 10386-10389, https://doi.org/10.1039/C4CC02724H

[12] E. Camps, S.E. Rodil, J.A. Salas, H.V. Estrada, A detailed study of the synthesis of Bismuth thin films by PVD-methods and their structural characterization, Mater. Res. Soc. Symp. Proc. 1477 (2012) 21-27, https://doi.org/10.1557/opl.2012.1703

[13] A.S. Fedotov, S.K. Poznyak, L.S. Tsybulskaya, V.G. Shepelevich, I.A. Svito, A. Saad, A.V. Mazanik, A.K. Fedotov, Polycrystalline bismuth films: Correlation between grain structure and electron transport, Phys. Status Solidi Basic Res. 252 (2015) 2000-2005, https://doi.org/10.1002/pssb.201552051

[14] I. Švancara, C. Prior, S.B. Hočevar, J. Wang, A decade with bismuth-based electrodes in electroanalysis, Electroanalysis 22 (2010) 1405-1420, https://doi.org/ 10.1002/elan.200970017

[15] F. Xiao, C. Hangarter, B. Yoo, Y. Rheem, K.H. Lee, N.V. Myung, Recent progress in electrodeposition of thermoelectric thin films and nanostructures, Electrochim Acta 53 (2008) 8103-8117, https://doi.org/10.1016/j.electacta.2008.06.015

[16] A.S. Fedotov, V. Shepelevich, S. Poznyak, L. Tsybulskaya, A. Mazanik, I. Svito, S. Gusakova, P. Zukowski, T.N. Koltunowicz, Simulation of polycrystalline bismuth films Seebeck coefficient based on experimental texture identification, Mater. Chem. Phys. 177 (2016) 413-416, https://doi.org/10.1016/j.matchemphys.2016.04.047

[17] J.P. McCaffrey, E. Mainegra-Hing, H. Shen, Optimizing non-Pb radiation shielding materials using bilayers, Med. Phys. 36 (2009) 5586-5594, https://doi.org/10. $1118 / 1.3260839$

[18] J.P. McCaffrey, F. Tessier, H. Shen, Radiation shielding materials and radiation scatter effects for interventional radiology (IR) physicians, Med. Phys. 39 (2012) 4537-4546, https://doi.org/10.1118/1.4730504

[19] D.I. Tishkevich, S.S. Grabchikov, E.A. Grabchikova, D.S. Vasin, S.B. Lastovskiy, A.S. Yakushevich, D.A. Vinnik, T.I. Zubar, I.V. Kalagin, S.V. Mitrofanov, D.V. Yakimchuk, A.V. Trukhanov, Modeling of paths and energy losses of highenergy ions in single-layered and multilayered materials, IOP Conf. Ser.: Mater. Sci. Eng. 848 (2020) 012089, https://doi.org/10.1088/1757-899X/848/1/012089

[20] D. Tishkevich I., A. Vorobjova I., D. Vinnik A., Template assisted Ni nanowires fabrication, Mater. Sci. Forum. 946 (2019) 235-241, https://doi.org/10.4028/ www.scientific.net/MSF.946.235

21 T. Flores, M. Arronte, E. Rodriguez, L. Ponce, J.C. Alonso, C. Garcia, M. Fernandez, E., Haro, Bismuth thin films obtained by pulsed laser deposition. Guzman, A.M., Ed.; Cartagena de Indias, Colombia, 1999; 70-73.

[22] T. Kuznetsova A., T. Zubar I., V. Lapitskaya A., K. Sudzilouskaya A., S. Chizhik A. A. Didenko L., V. Svetlichnyi M., M. Vylegzhanina E., V. Kudryavtsev V., T. Sukhanova E., Tribological properties investigation of the thermoplastic 
elastomers surface with the AFM lateral forces mode, IOP Conf. Ser.: Mater. Sci. Eng. 256 (2017) 012022, https://doi.org/10.1088/1757-899X/256/1/012022

[23] V.M. Grabov, E.V. Demidov, V.A. Komarov, D.Y. Matveev, A.A. Nikolaeva, D. Markushevs, E.V. Konstantinov, E.E. Konstantinova, Size effect in galvanomagnetic phenomena in bismuth films doped with tellurium, Semiconductors 48 (2014) 630-635, https://doi.org/10.1134/S106378261405008X

[24] A.S. Fedotov, V.G. Shepelevich, I.A. Svito, V.A. Sivakov, Temperature dynamics of the electronic structure in dilute Bi-Sn alloys, Phys. Rev. B. 97 (2018) 1-15, https://doi.org/10.1103/PhysRevB.97.075204

[25] P. Kuppusami, V.S. Raghunathan, Status of pulsed laser deposition: Challenges and opportunities, Surf. Eng. 22 (2006) 81-83, https://doi.org/10.1179/ 174329406 X98502

[26] V.G. Shepelevich, J. Wang, Structure, microhardness, and stability of rapidly solidified In-Sb foils, Inorg. Mater. 46 (2010) 339-342, https://doi.org/10.1134/ S0020168510040023

[27] D. Tishkevich I., A. Vorobjova I., A. Trukhanov V., Thermal stability of nanocrystalline nickel electrodeposited into porous alumina, Solid State Phenom 299 (2020) 281-286, https://doi.org/10.4028/www.scientific.net/SSP.299.281

[28] D.S. Jayakrishnan, Electrodeposition: the Versatile Technique for Nanomaterials, Woodhead Publishing Limited, 2012, https://doi.org/10.1533/9780857095800. 1.86

[29] D. Tishkevich I., A. Vorobjova I., D. Vinnik A., Formation and corrosion behavior of Nickel/Alumina nanocomposites, Solid State Phenom. 299 (2020) 100-106, https://doi.org/10.4028/www.scientific.net/SSP.299.100

[30] E. Sandnes, M.E. Williams, U. Bertocci, M.D. Vaudin, G.R. Stafford, Electrodeposition of bismuth from nitric acid electrolyte, Electrochim. Acta 52 (2007) 6221-6228, https://doi.org/10.1016/j.electacta.2007.04.002

[31] C. Agapescu, A. Cojocaru, A. Cotarta, T. Visan, Electrodeposition of bismuth, tellurium, and bismuth telluride thin films from choline chloride-oxalic acid ionic liquid, J. Appl. Electrochem. 43 (2013) 309-321, https://doi.org/10.1007/ s10800-012-0487-0

[32] A. Vorobjova I., D. Shimanovich L., O. Sycheva A., T. Ezovitova I., D. Tishkevich I., A. Trykhanov V., Studying the thermodynamic properties of composite magnetic material based on anodic alumina, Russ. Microelectron. 48 (2019) 107-118, https://doi.org/10.1134/S1063739719020100

[33] S. Jiang, Y.H. Huang, F. Luo, N. Du, C.H. Yan, Synthesis of bismuth with various morphologies by electrodeposition, Inorg. Chem. Commun. 6 (2003) 781-785, https://doi.org/10.1016/S1387-7003(03)00104-7

[34] D.I. Tishkevich, S.S. Grabchikov, L.S. Tsybulskaya, V.S. Shendyukov, S.S. Perevoznikov, S.V. Trukhanov, E.L. Trukhanova, A.V. Trukhanov, D.A. Vinnik, Electrochemical deposition regimes and critical influence of organic additives on the structure of Bi films, J. Alloy. Compd. 735 (2018) 1943-1948, https://doi.org/ 10.1016/j.jallcom.2017.11.329

[35] D.I. Tishkevich, S.S. Grabchikov, S.B. Lastovskii, S.V. Trukhanov, T.I. Zubar, D.S. Vasin, A.V. Trukhanov, A.L. Kozlovskiy, M.M. Zdorovets, Effect of the synthesis conditions and microstructure for highly effective electron shields production based on Bi coatings, ACS Appl. Energy Mater. 1 (2018) 1695-1702, https://doi.org/10.1021/acsaem.8b00179

[36] B. Youbi, Y. Lghazi, A. El Bachiri, M. Ait Himi, O. Elibrizy, I. Bimaghra, Investigation of nucleation and growth mechanism of bismuth electrodeposited on ITO substrate in nitric acid medium, Mater. Today Proc. 22 (2020) 6-11, https://doi.org/10.1016/j.matpr.2019.08.055

[37] M. Nedelcu, M. Sima, A.S. Manea, M.F. Lazarescu, R.V. Ghita, F. Craciunoiu, T. Visan, Bi2-XSbxTe3 thick thermoelectric films obtained by electrodeposition from hydrochloric acid solutions, J. Optoelectron. Adv. Mater. 4 (2002) 99-106.

[38] C.G. Fink, O.H. Gray Co-deposition, of lead and bismuth, Trans. Electrochem. Soc. 62 (1932) 123-128.

[39] M. Yang, Z. Hu, Electrodeposition of bismuth onto glassy carbon electrodes from nitrate solutions, J. Electroanal. Chem. 583 (2005) 46-55, https://doi.org/10. 1016/j.jelechem.2005.04.019

[40] D.I. Tishkevich, S.S. Grabchikov, S.B. Lastovskii, S.V. Trukhanov, T.I. Zubar, D.S. Vasin, A.V. Trukhanov, Correlation of the synthesis conditions and microstructure for Bi-based electron shields production, J. Alloy. Compd. 749 (2018) 1036-1042, https://doi.org/10.1016/j.jallcom.2018.03.288

[41] C.F. Gallo, B.S. Chandrasekhar, P.H. Sutter, Transport properties of bismuth single crystals, J. Appl. Phys. 34 (1963) 144-152, https://doi.org/10.1063/1.1729056

[42] P. Cucka, C.S. Barrett, The crystal structure of $\mathrm{Bi}$ and of solid solutions of $\mathrm{Pb}, \mathrm{Sn}$, $\mathrm{Sb}$ and Te in Bi, Acta Crystallogr 15 (1962) 865-872, https://doi.org/10.1107/ s0365110x62002297

[43] T. Ungár, Microstructural parameters from X-ray diffraction peak broadening, Scr. Mater. 51 (2004) 777-781, https://doi.org/10.1016/j.scriptamat.2004.05.007
[44] R. Rudman, Handbook of X-rays, for diffraction, emission, absorption, and microscopy (Kaelble, Emmett F., ed), J. Chem. Educ. 45 (1968) 443, https://doi.org/ 10.1021/ed045p443.2

[45] B. O'Brien, M. Plaza, L.Y. Zhu, L. Perez, C.L. Chien, P.C. Searson, Magnetotransport properties of electrodeposited bismuth films, J. Phys. Chem. C 112 (2008) 12018-12023, https://doi.org/10.1021/jp802802j

[46] L.M. Gades, T.W. Cecil, R. Divan, D.R. Schmidt, J.N. Ullom, T.J. Madden, D. Yan, A. Miceli, A novel method to detect functional microRNA regulatory modules by bicliques merging, IEEE/ACM Trans. Comput. Biol. Bioinform 13 (2016) 549-556, https://doi.org/10.1109/TASC.2017.2662007

[47] D. Tishkevich, S. Grabchikov, T. Zubar, D. Vasin, S. Trukhanov, A. Vorobjova, D. Yakimchuk, A. Kozlovskiy, M. Zdorovets, S. Giniyatova, D. Shimanovich D. Lyakhov, D. Michels, M. Dong, S. Gudkova, A. Trukhanov, Early-stage growth mechanism and synthesis conditions-dependent morphology of nanocrystalline Bi films electrodeposited from perchlorate electrolyte, Nanomaterials 10 (2020) 1-17, https://doi.org/10.3390/NAN010061245

[48] Y. Hasegawa, Y. Ishikawa, T. Saso, H. Shirai, H. Morita, T. Komine, H. Nakamura, A method for analysis of carrier density and mobility in polycrystalline bismuth, Phys. B Condens. Matter 382 (2006) 140-146, https://doi.org/10.1016/j.physb. 2006.02.011

[49] S. Kochowski, A. Opilski, Concentration and mobility of charge carriers in thin polycrystalline films of bismuth, Thin Solid Films 48 (1978) 345-351, https://doi. org/10.1016/0040-6090(78)90014-7

[50] K. Seeger, Semiconductor Physics: An Introduction, Advanced Texts in Physics, 9 ed., Springer, Berlin, 2010 ISBN 978-3-662-09855-4.

[51] N.W. Ashcroft, N.D. Mermin, Solid state physics Holt, Rinehart and Winston, New York, XXII, 826 Seiten, Physik in unserer Zeit 9 (1978), https://doi.org/10.1002/ piuz.19780090109

[52] T. Arisaka, M. Otsuka, Y. Hasegawa, Investigation of carrier scattering process in polycrystalline bulk bismuth at $300 \mathrm{~K}$, J. Appl. Phys. 123 (2018) 0-10, https://doi. org/10.1063/1.5032137

[53] J. Heremans, O.P. Hansen, Temperature dependence of excess carrier density and thermopower in tin-doped bismuth. Pseudo-parabolic model, J. Phys. C Solid State Phys. 16 (1983) 4623-4636, https://doi.org/10.1088/0022-3719/16/23/022

[54] C.M. Hurd, The Hall Effect in Metals and Alloys, Springer US, Boston, MA, 1972 ISBN 978-1-4757-0467-9.

55 B. Cui, M. Grayson, Background subtraction in Fourier-domain mobility spectrum analysis for resolving low-mobility carriers. In Proceedings of the Proceedings SPIE 10111; Razeghi, M., Ed., 2017; 101110N.

[56] B.S. Cunningham, Quantitative Mobility Spectrum Analysis of III-V Heterostructures on Silicon, Texas State University, San Marcos, Texas, 2012.

[57] I. Vurgaftman, J.R. Meyer, C.A. Hoffman, D. Redfern, J. Antoszewski, L. Faraone J.R. Lindemuth, Improved quantitative mobility spectrum analysis for hall characterization, J. Appl. Phys. 84 (1998) 4966-4973, https://doi.org/10.1063/1. 368741

[58] J.W. McClure, Field dependence of magnetoconductivity, Phys. Rev. 101 (1956) 1642-1646, https://doi.org/10.1103/PhysRev.101.1642

59 〈https://resources.wolframcloud.com/FunctionRepository/resources/ MultiNonlinearModelFit>.

[60] H. Asahi, A. Kinbara, Size effect in the electrical properties of thin epitaxial bismuth films, Thin Solid Films 66 (1980) 131-137, https://doi.org/10.1016/00406090(80)90215-1

[61] D.L. Partin, J. Heremans, D.T. Morelli, C.M. Thrush, C.H. Olk, T.A. Perry, Growth and characterization of epitaxial bismuth films, Phys. Rev. B 38 (1988) 3818-3825.

[62] A. Vorobjova, D. Tishkevich, D. Shimanovich, T. Zubar, K. Astapovich, A. Kozlovskiy, M. Zdorovets, A. Zhaludkevich, D. Lyakhov, D. Michels, D. Vinnik, V. Fedosyuk, A. Trukhanov, The influence of the synthesis conditions on the magnetic behaviour of the densely packed arrays of Ni nanowires in porous anodic alumina membranes, RSC Adv. 11 (2021) 3952, https://doi.org/10.1039/d0ra07529a

[63] D. Tishkevich, A. Vorobjova, D. Shimanovich, E. Kaniukov, A. Kozlovskiy, M. Zdorovets, D. Vinnik, A. Turutin, I. Kubasov, A. Kislyuk, M. Dong, M. Sayyed I., T. Zubar, A. Trukhanov, Magnetic properties of the densely packed ultra-long $\mathrm{Ni}$ nanowires encapsulated in alumina membrane, Nanomaterials. 11 (2021) 1775, https://doi.org/10.3390/nano11071775

[64] A. Kozlovskiy L., I. Kenzhina E., M. Zdorovets V., M. Saiymova, D. Tishkevich I., S. Trukhanov V., A. Trukhanov V., Synthesis, phase composition and structural and conductive properties of ferroelectric microparticles based on ATiOx ( $A=B a$, Ca, Sr), Ceram Int. 45 (2019) 17236-17242, https://doi.org/10.1016/j.ceramint. 2019.05.279 